\title{
Preparation, Characterization, and In Vivo Pharmacoscintigraphy Evaluation of an Intestinal Release Delivery System of Prussian Blue for Decorporation of Cesium and Thallium
}

\author{
Nidhi Sandal,' Gaurav Mittal,' Aseem Bhatnagar, ${ }^{1}$ \\ Dharam Pal Pathak, ${ }^{2}$ and Ajay Kumar Singh ${ }^{1}$ \\ ${ }^{1}$ Department of Nuclear Medicine, Institute of Nuclear Medicine and Allied Sciences, Defence RéD Organisation, \\ Brig. SK Mazumdar Road, Delhi 110 054, India \\ ${ }^{2}$ Division of Pharmaceutical Chemistry, DIPSAR, MB Road, Pushp Vihar, New Delhi 110 017, India \\ Correspondence should be addressed to Gaurav Mittal; gauravmittal23@gmail.com
}

Received 9 August 2017; Revised 2 November 2017; Accepted 12 November 2017; Published 29 November 2017

Academic Editor: Ali Nokhodchi

Copyright ( $\odot 2017$ Nidhi Sandal et al. This is an open access article distributed under the Creative Commons Attribution License, which permits unrestricted use, distribution, and reproduction in any medium, provided the original work is properly cited.

Background. Prussian blue (PB, ferric hexacyanoferrate) is approved by US-FDA for internal decorporation of Cesium-137 ( ${ }^{137}$ Cs) and Thallium-201 $\left({ }^{201} \mathrm{Tl}\right)$. Aim. Since PB is a costly drug, pH-dependent oral delivery system of PB was developed using calcium alginate matrix system. Methods. Alginate (Alg) beads containing PB were optimized by gelation of sodium alginate with calcium ions and effect of varying polymer concentration on encapsulation efficiency and release profile was investigated. Scanning electron microscopy (SEM) was carried out to study surface morphology. Adsorption efficacy of Alg-PB beads for ${ }^{201} \mathrm{Tl}$ was evaluated and compared with native $\mathrm{PB}$. In vivo $\mathrm{pH}$-dependent release of the formulation was studied in humans using gamma scintigraphy. Results. Encapsulation efficiencies of Alg-PB beads with 0.5, 1.0, 1.5, and 2.0\% polymer solution were 99.9, 91, 92, and 93\%, respectively. SEM and particle size analysis revealed differences between formulations in their appearance and size distribution. No drug release was seen in acidic media ( $\mathrm{pH}$ of 1-2) while complete release was observed at $\mathrm{pH}$ of 6.8. Dissolution data was fitted to various mathematical models and beads were found to follow Hixson-Crowell mechanism of release. The $\mathrm{pH}$-dependent release of beads was confirmed in vivo by pharmacoscintigraphy in humans.

\section{Introduction}

Prussian blue (ferric hexacyanoferrate) is a dye used for the internal decorporation of Cesium-137 $\left({ }^{137} \mathrm{Cs}\right)$ and Thallium$201\left({ }^{201} \mathrm{Tl}\right)[1,2]$. It is a crystal lattice that exchanges potassium for cesium at the surface of the crystal [3]. Prussian blue (PB) can be administered in two different physicochemical forms, namely, soluble (colloidal) and insoluble (noncolloidal), both being equally effective in vivo $[2,4]$. Differences in quality of preparation, particle size, and local $\mathrm{pH}$ affect cesium adsorption to the $\mathrm{PB}$ crystal lattice and may explain some of the variability in its efficacy seen among patients [5]. On the basis of its very high affinity for cesium and thallium, USFDA has approved insoluble PB for the removal of ${ }^{137} \mathrm{Cs}$ and
${ }^{201} \mathrm{Tl}$. These ions are ordinarily excreted into the intestine and reabsorbed from the gut into the blood and then excreted again into the GI tract. Orally administered PB traps thallium or cesium in the gut, interrupts its reabsorption from the gastrointestinal tract and thereby increasing its excretion through feces. Thus, the biological half-life of thallium and cesium is significantly reduced after decorporation therapy with PB. PB itself is not absorbed across the gut wall in significant amounts $[6,7]$.

Insoluble PB has been used both in animals and clinically in humans, including during the Goiania incident in Brazil, in which 104 individuals showed evidence of internal contamination with radiocesium $[8,9]$. Analysis of the data with respect to PB therapy has revealed that increasing PB dose did 
not lead to any appreciable decrease in the biological half-life of ${ }^{137} \mathrm{Cs}[10]$. Also, $\mathrm{pH}$ has been reported to be a major factor that affects the efficacy of $\mathrm{PB}$ in vivo [11].

Since PB is a costly drug and may not be easily available as a pharmaceutical grade chemical, it was thought worthwhile to design and evaluate a $\mathrm{pH}$-dependent release oral dosage form of $\mathrm{PB}$. Moreover, since the site of action of $\mathrm{PB}$ is intestines, the aim was to release PB directly in the intestine, whereby the drug is delivered at the exact site of action, giving rise to a possibility of reducing the dose in comparison to the present regime wherein a lot of drug gets wasted in the stomach milieu $[2,6]$.

In the present study, we have prepared $\mathrm{pH}$-dependent oral delivery system of PB by using alginate as a polymer. Alginate has been routinely used in biomedical applications because of its nontoxic and biodegradable nature when given orally $[12,13]$. Alginate gel beads are commonly obtained by dropping solutions of sodium alginate into solutions of calcium chloride $[1,14]$. These gel beads shrink at acidic $\mathrm{pH}$ and get eroded at alkaline $\mathrm{pH}$. Therefore, these can be used effectively to deliver drugs in the intestine, which has a $\mathrm{pH}$ of $>6.7$. Using the same principle, we have prepared beads of calcium alginate-Prussian blue (Alg-PB) in different ratios and characterized them for encapsulation efficiency, surface morphology and in vitro dissolution profile. $\mathrm{pH}$ dependent release of Alg-PB beads was studied at $\mathrm{pH}$ of 3 , $4,5,6$, and 7 in vitro. The adsorption efficacy of Alg-PB beads for ${ }^{201} \mathrm{Tl}$ was evaluated and compared with native PB. In vivo $\mathrm{pH}$-dependent release characteristic of the formulation was studied in humans using gamma scintigraphy. Thus $\mathrm{pH}$ dependent release delivery system of PB was developed and evaluated both in vitro and in vivo.

\section{Material and Methods}

The drug substance, Prussian blue (ferric hexacyanoferrate), was procured from John Bakers, Colorado, USA. Sodium alginate was purchased from Loba Chemie, Bombay, India. Sodium hydroxide, sulphuric acid, and other reagents of analytical grade were purchased from local suppliers.

\subsection{Preparation and Characterization of Alginate Gel Beads.} One gram $\mathrm{PB}$ was added to $10 \mathrm{ml}$ of sodium alginate aqueous solution of varying concentration, namely, $0.5,1.0,1.5$, or $2.0 \% \mathrm{w} / \mathrm{v}$, respectively, so as to select the final drug: polymer ratio depending upon the desired release characteristics. Each solution was mixed and vortexed thoroughly for 5-10 min. The solution was then dropped through a $21 \mathrm{G}$ needle into $10 \%$ w/w $\mathrm{CaCl}_{2}$ solution, which was being continuously stirred. These droplets of the mixture formed gel beads instantaneously. Beads were allowed to sink, filtered, and washed 2-3 times with distilled water before drying at room temperature for $12 \mathrm{~h}$. Surface morphology of dried hydrogel beads was determined by scanning electron microscopy (Jeol JSM-840).

2.2. Drug Loading and Encapsulation Efficiency. One mg of powdered beads was dissolved in $1 \mathrm{ml}$ of $4 \mathrm{~N} \mathrm{NaOH} .200 \mu \mathrm{L}$ of concentrated sulphuric acid was added after 10 min of incubation. The volume was made up to $10 \mathrm{ml}$ with distilled water and absorbance was taken at $710 \mathrm{~nm}$ as per previously reported method [15]. Concentration of PB was read from the absorbance versus concentration standard plot of $\mathrm{PB}$ and hence the PB content was calculated in $1 \mathrm{mg}$ beads. The encapsulation and loading efficiency were calculated as follows:

$$
\begin{aligned}
& \text { Drug loaded }=\frac{\text { Drug content }(\text { calculated }) \times 100}{\text { Wt of the beads }} \\
& \text { Encapsulation efficiency } \\
& \qquad=\frac{\text { Drug content }(\text { calculated }) \times 100}{\text { Amount of drug added }} .
\end{aligned}
$$

2.3. SEM Studies of Beads. Scanning electron microscopy (SEM) was carried out to study the surface morphology of beads. Samples were mounted on an aluminum stage using adhesive carbon tape and placed in a low humidity chamber for $12 \mathrm{~h}$ prior to analysis. Samples were coated with gold-palladium for $60 \mathrm{~s}$ under an argon atmosphere using an Emscope ${ }^{\circledR}$ Model 500 Sputter Coater in a high vacuum evaporator equipped with an omnirotary stage tray. SEM was performed using a Jeol JSM-840 scanning microscope (Jeol, Ltd.) operating at an accelerating voltage of $10 \mathrm{kV}$ and a $30 \mu \mathrm{A}$ and $29 \mu \mathrm{m}$ emission current. Images were captured with Quartz ${ }^{\circledR}$ software. It was used to evaluate surface texture, shape, and average size of particles. The cross-sectional view of the beads was also studied using SEM.

2.4. Release Studies. In vitro drug release studies were performed in triplicate for each of the four test formulations using the USP XXIII dissolution apparatus Type 2 (Scientific Systems 8S) at $75 \mathrm{rpm}$ as per International Conference on Harmonization (ICH) guidelines [16]. The media used were $500 \mathrm{ml}$ deaerated $0.1 \mathrm{M} \mathrm{HCl}$ (pH of 1.2), which was maintained at $37^{\circ} \mathrm{C}$ for first $2 \mathrm{~h}$ and then replaced with $\mathrm{pH} 6.8$ phosphate buffer. Approximately, $0.5 \mathrm{~g}$ beads were used for each experiment. Samples $(5 \mathrm{ml})$ were taken at different time intervals and assayed spectrophotometrically at $710 \mathrm{~nm}$ as described in previous section. At each time of withdrawal, $5 \mathrm{ml}$ of fresh medium was replaced into the dissolution apparatus to maintain sink condition.

In another set of experiments, $\mathrm{pH}$ dependence of release was studied in citrate-phosphate buffers of $\mathrm{pH} 3,4,5,6$, and 7. $0.5 \mathrm{~g}$ of $1 \% \mathrm{~PB}-\mathrm{Alg}$ beads were subjected to dissolution studies as described above and concentration of PB was determined as per the method described by Nagaraja et al. [15].

2.5. Analysis of Release Mechanism. The release mechanism of $\mathrm{PB}$ from $0.5,1,1.5$, and $2 \%$ Alg-PB beads was examined in accordance with the kinetic models. The regression coefficient, $R^{2}$ value nearer to 1.0 , indicated the model fitting of the release mechanism. The commonly adopted models for understanding the release of drugs from matrices, namely, zero-order equation, first-order equation [17, 18], Higuchi 
TABLE 1: Drug loading and encapsulation efficiency of PB loaded alginate beads.

\begin{tabular}{|c|c|c|c|c|}
\hline & \multicolumn{4}{|c|}{ Formulation } \\
\hline & A & B & $\mathrm{C}$ & $\mathrm{D}$ \\
\hline Percentage of sodium alginate solution & $0.5 \%$ & $1 \%$ & $1.5 \%$ & $2 \%$ \\
\hline (1) Drug loaded $(\% \mathrm{w} / \mathrm{w})$ & $94.90 \pm 0.96$ & $81.93 \pm 0.39$ & $78.69 \pm 1.07$ & $74.96 \pm 0.18$ \\
\hline (2) Encapsulation efficiency & $99.89 \pm 1.02$ & $91.03 \pm 0.45$ & $92.58 \pm 0.31$ & $93.69 \pm 0.60$ \\
\hline
\end{tabular}

equation [19], Hixson-Crowell equation [20], Weibull equation [21], and Korsmeyer-Peppas simple exponential equation $[22,23]$, were used to elucidate the mode of release using SigmaPlot TM-10 software (Cranes Software International, Bangalore, India).

2.6. In Vitro Binding Efficacy of Alg-PB Beads. Three sets of $1 \mathrm{mg}$ of the powdered Alg-PB beads' formulations A, B, C, and $\mathrm{D}$ each were incubated with $10 \mathrm{MBq}^{201} \mathrm{Tl}$ in $5 \mathrm{ml}$ of saline. $5 \mathrm{ml}$ saline ( $\mathrm{pH}$ of 6-7) having $10 \mathrm{MBq}^{201} \mathrm{Tl}$ was used as negative control and $1 \mathrm{mg}$ native $\mathrm{PB}$ in saline containing $10 \mathrm{MBq}{ }^{201} \mathrm{Tl}$ was used as positive control. $500 \mu \mathrm{l}$ of the sample was withdrawn from each after $1 \mathrm{~h}$ (equilibrium time) and centrifuged [2]. Radioactivity was measured in $100 \mu \mathrm{l}$ of the supernatant using a well type gamma ray spectrometer (ECIL, India). Percentage adsorption was calculated by dividing the radioactive counts of supernatant of the test by that of negative control.

2.7. Pharmacoscintigraphy Evaluation. In vivo $\mathrm{pH}$-dependent release of Alg-PB beads was studied in healthy human volunteers by gamma scintigraphy using technetium pertechnetate $\left({ }^{99} \mathrm{mcO}_{4}{ }^{-}\right)$. The study protocol was approved by the Institutional Human Ethics Committee duly constituted for the purpose vide letter no. INM/TS/IEC/005/07.

2.7.1. Preparation of Radiolabeled Beads. Beads were prepared containing $37 \mathrm{MBq}^{99 \mathrm{~m}} \mathrm{TcO}_{4}{ }^{-}$and washed thoroughly with distilled water before drying. $1 \% \mathrm{w} / \mathrm{v}$ alginate solution containing $1 \mathrm{~g}$ of $\mathrm{PB}$ and ${ }^{99 \mathrm{~m}} \mathrm{TcO}_{4}{ }^{-}$was dropped in $10 \% \mathrm{w} / \mathrm{v} \mathrm{CaCl}$ solution of $1 \mathrm{~N} \mathrm{HCl}$. The beads were formed and separated by filtration. The beads were washed thoroughly with distilled water to remove adhering pertechnetate ions and dried at room temperature for $12 \mathrm{~h}$. In vitro release kinetics of radioactivity were studied as described in Section 2.4.

2.7.2. Release Profile of Labeled Dosage Forms. In vitro release profile of radiolabeled dosage form was determined by measuring radioactive counts released at regular time intervals of $15 \mathrm{~min}$ till $3 \mathrm{~h} .0 .1 \mathrm{~N} \mathrm{HCl}$ was used as dissolution media (Scientific Systems 8S) for first $2 \mathrm{~h}$ followed by phosphate buffer of $\mathrm{pH} 6.8$. The study was carried out at $75 \mathrm{rpm}$ and $37^{\circ} \mathrm{C} .1 \mathrm{ml}$ samples were withdrawn and measured for radioactive counts in gamma ray spectrometer (ECIL, India). The release pattern of activity was compared to the drug release.

2.7.3. Gamma Scintigraphy. Three healthy human volunteers were given orally $200 \mathrm{mg}$ of ${ }^{99 \mathrm{~m}} \mathrm{Tc}$-labeled Alg-PB beads having $37 \mathrm{MBq}^{99} \mathrm{TcO}_{4}{ }^{-}$. In control group, $37 \mathrm{MBq}$ of liquid ${ }^{99} \mathrm{mcO}_{4}{ }^{-}$was administered orally. 64 frames each of $30 \mathrm{sec}$ dynamic images were taken of the abdominal area. Blood pool activity of control and the test subjects was monitored with respect to GIT transit of beads. A region of interest was marked over liver and counts/sec versus time graph was plotted using software eNTEGRA version 2.5.

2.8. Statistical Analysis. Data are expressed as mean \pm SD. Unpaired $t$-test was applied for the calculation of significance at $p<0.05$ using GraphPad Instat version 3.00 for Windows XP, GraphPad Software, San Diego, California, USA.

\section{Results and Discussion}

3.1. Drug Loading and Encapsulation Efficiency. Table 1 represents the data with respect to drug loading and encapsulation efficiency of PB loaded alginate beads. An encapsulation efficiency of $99.89 \%, 91.03 \%, 92.58 \%$, and $93.69 \%$ was achieved with $0.5,1.0,1.5$, and $2.0 \%$ polymer solution, respectively, for PB. However, an increase in polymer content inversely affected the percentage of drug loaded with 94.9, 81.93, 78.69, and $74.96 \%$ of the drug being loaded $(\mathrm{w} / \mathrm{w})$ in case of $0.5 \%$, $1 \%, 1.5 \%$, and $2 \%$ alginate conc., respectively. Using $0.5 \%$ alginate conc. resulted in beads being fragile, with a high degree of wear and tear even while preparing the sample. On the other hand, 1\% PB-Alg beads not only exhibited good encapsulation efficiency for Prussian blue, but proper beads were also formed. Since pourability of $1.5 \%$ and $2 \%$ PBalginate suspensions was poor as compared to $1 \% \mathrm{~PB}$-alginate suspension; therefore, $1 \% \mathrm{~PB}$-Alg beads were selected as the final formulation for further studies.

3.2. Surface Morphology. The PB-alginate beads were characterized for their morphological properties by scanning electron microscopy (SEM). In order to investigate the morphology and gain insight into the PB-Alg beads, SEM analysis of void alginate beads and $\mathrm{PB}$ encapsulated alginate beads was studied. The diameter of beads varied from 1.2 to $1.5 \mathrm{~mm}$ as the alginate concentration was increased from 1 to $2 \%$. The $0.5 \%$ polymer beads as observed under SEM were found to be fragile and had a high degree of wear and tear even while preparing the sample (Figure 1(a)). 1\% alginate polymer beads were found to be optimal because they had sufficient strength and intactness and maximum PB content of $91 \%$ could be incorporated into them. 1.5 and $2 \%$ beads were a bit harder and the pourability of polymer solution containing drug through $21 \mathrm{G}$ needle was poor in their cases. However, no significant difference was observed 


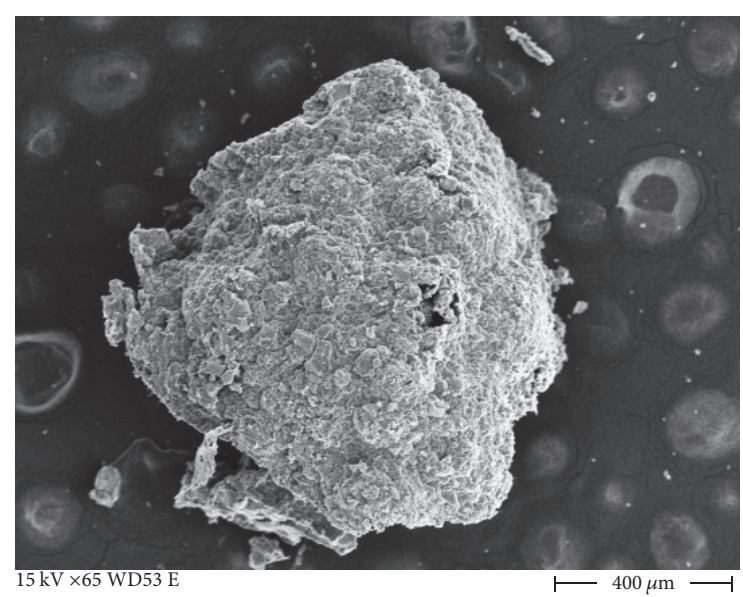

(a)

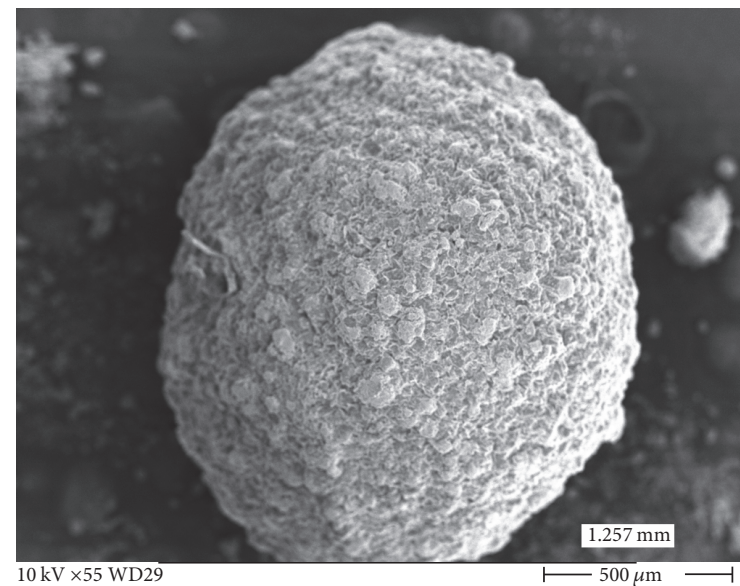

(c)

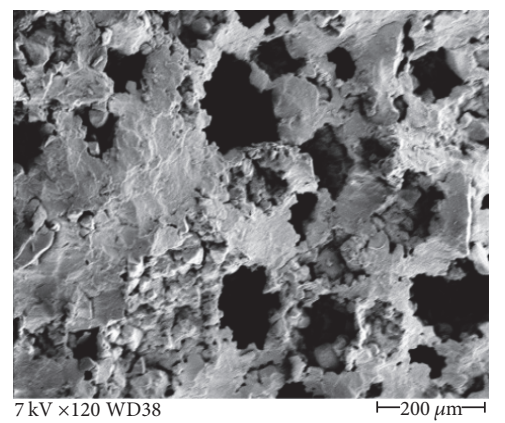

(e)

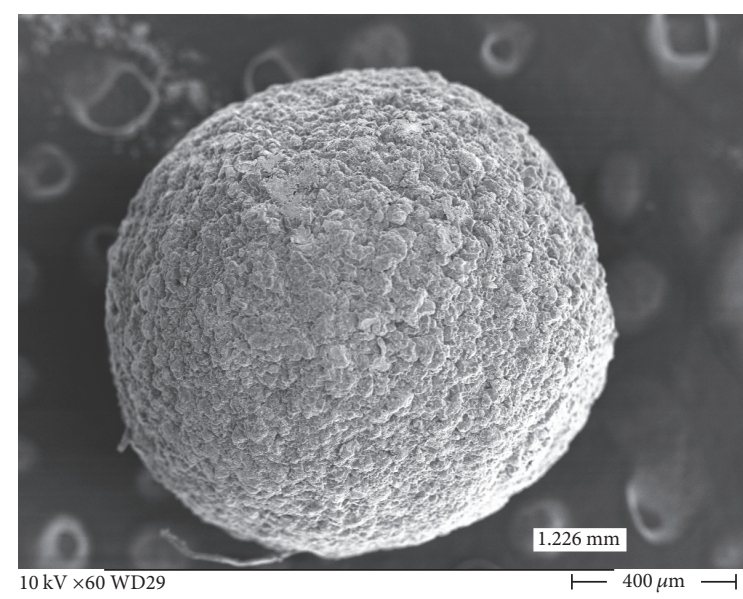

(b)

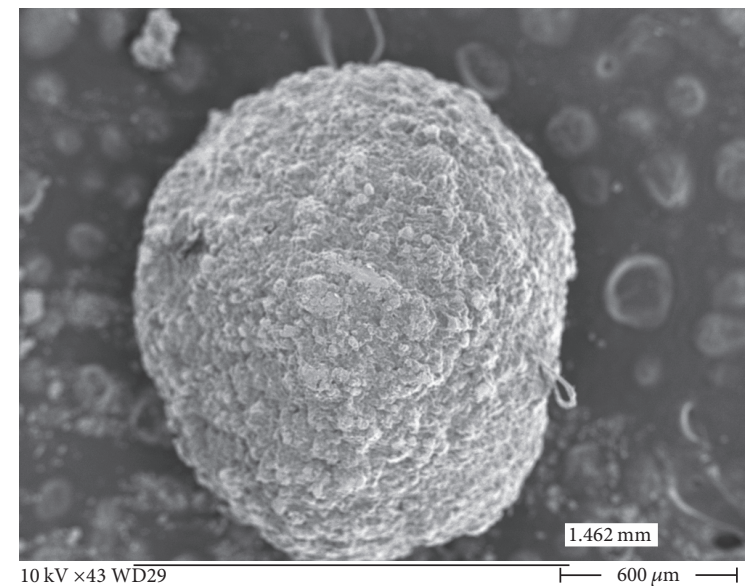

(d)

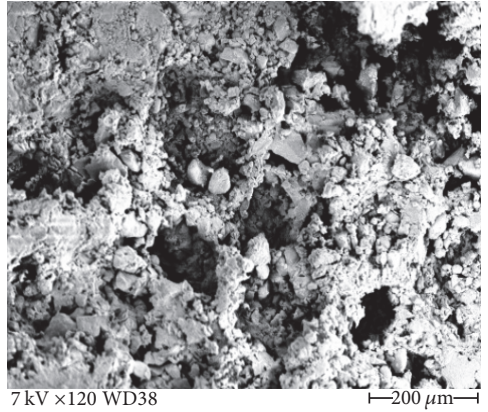

(f)

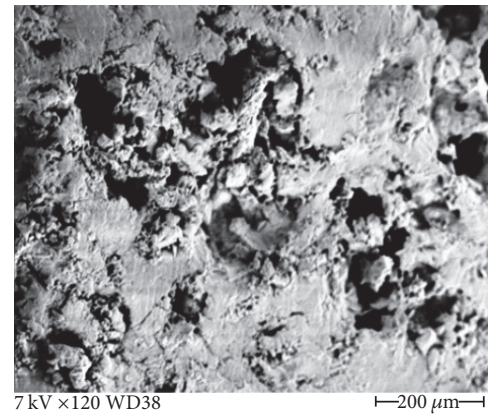

(g)

Figure 1: SEM micrographs of (a) $0.5 \%$, (b) $1 \%$, (c) $1.5 \%$, and (d) $2 \%$ PB-Alg beads and cross-sectional view of (e) $1 \%$, (f) $1.5 \%$, and (g) $2 \%$ PB-Alg beads.

in surface morphology of beads having $1,1.5$, and $2 \%$ polymer concentration (Figures $1(\mathrm{a})-1(\mathrm{~d})$ ). From the cross-sectional view of the beads under SEM, it was observed that the porosity decreased with increase in polymer concentration (Figures 1(e)-1(g)).

Surface morphologies of drug loaded $1 \%$ polymer beads and void beads were also compared. PB loaded beads had rugged surface whereas void beads had comparatively far smoother surface. No pores were visible in the void beads whereas PB loaded beads were porous. The pores present in drug loaded beads may help in fast release of $\mathrm{PB}$ at $\mathrm{pH}$ 6.8. However, void alginate beads were hard and did not erode easily.

3.3. Release Studies. Despite their different compositions, the beads having varying concentration of sodium alginate $[0.5 \%$ (A), $1 \%(\mathrm{~B}), 1.5 \%(\mathrm{C})$, and $2 \%(\mathrm{D})]$ and PB showed more or less similar release behavior (Figure 2). The $\mathrm{pH}$-dependent 


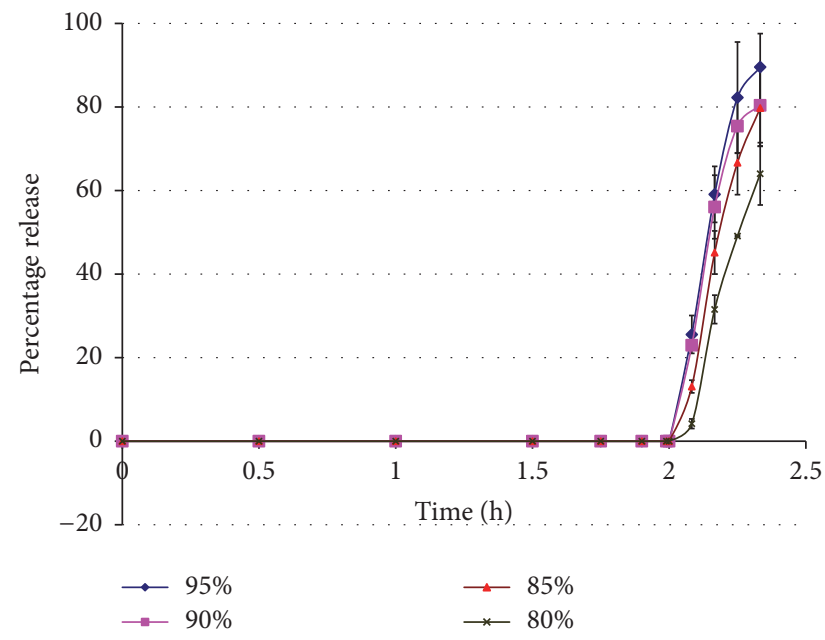

FIgURE 2: Cumulative percent release of PB from Alg-PB beads. Error bars represent standard deviation about the means based on 3 $\times 6$ replicates. The $\mathrm{pH}$ of dissolution media is 1-2 till $2 \mathrm{hrs}$. Thereafter $\mathrm{pH}$ of the dissolution media changes to 6.8 , wherein $\mathrm{PB}$ gets released immediately.

release studies of $\mathrm{PB}$ encapsulated in alginate beads were conducted in $0.1 \mathrm{~N} \mathrm{HCl}$ for the first 2 hours followed by a different dissolution media, that is, phosphate buffer of $\mathrm{pH}$ 6.8. In all cases a $\mathrm{pH}$-dependent drug release was seen. For the first 2 hours of dissolution in $0.1 \mathrm{~N} \mathrm{HCl}$, no $\mathrm{PB}$ was released. With the change in dissolution media to phosphate buffer of pH 6.8 , in next $5 \mathrm{~min}, 31 \%, 26.57 \%, 13.08 \%$, and $7.48 \%$ of $\mathrm{PB}$ was released, respectively, in case of A, B, C, and D whereas complete drug got released within $30 \mathrm{~min}$ in all the four formulations. There was little difference in release kinetics of all the formulations, indicating a very mild influence of difference in sodium alginate concentration.

In the experiment where $\mathrm{pH}$-dependent release of $1 \% \mathrm{~PB}$ Alg beads was studied using citrate-phosphate buffer of $\mathrm{pH}$ of $3,4,5,6$, and 7, no $\mathrm{PB}$ was released till $30 \mathrm{~min}$ at $\mathrm{pH} 3$ and only $0.3 \%$ release was observed after $90 \mathrm{~min}$. Even at $\mathrm{pH}$ 4 only $6.27 \%$ of the drug was released at the end of $90 \mathrm{~min}$. The rate of release of the drug at $\mathrm{pH} 5$ was slower than $\mathrm{pH}$ of 6 and 7. Approximately $95 \%$ of the drug got released at $\mathrm{pH}$ of 6 and 7 within $30 \mathrm{~min}$. This further corroborates our observation of release of $\mathrm{PB}$ in $\mathrm{pH} 6.8$ phosphate buffer. The results obtained confirm that the beads showed a $\mathrm{pH}$ dependent release pattern (Figure 3).

Although many other $\mathrm{pH}$-dependent eroding polymers in varying conc., namely, hydroxy propyl methylcellulose phthalate (HPMCP), cellulose acetate phthalate, and eudragit, were tried, none of them was able to achieve the desired $\mathrm{pH}$-dependent release of $\mathrm{PB}$. For example, while use of 2.5 and $5 \% \mathrm{w} / \mathrm{w}$ of HPMCP showed complete release of PB in acidic media, not only did 7.5 and $10 \%$ w/w HPMCP matrix tablets of $\mathrm{PB}$ restrict the release of drug in acidic $\mathrm{pH}$, they also did the same at $\mathrm{pH} 6.8$, thereby defeating the very objective of undertaking this work.

Sodium alginate was chosen for its ability to form a gel/meshwork in the presence of divalent cations such as

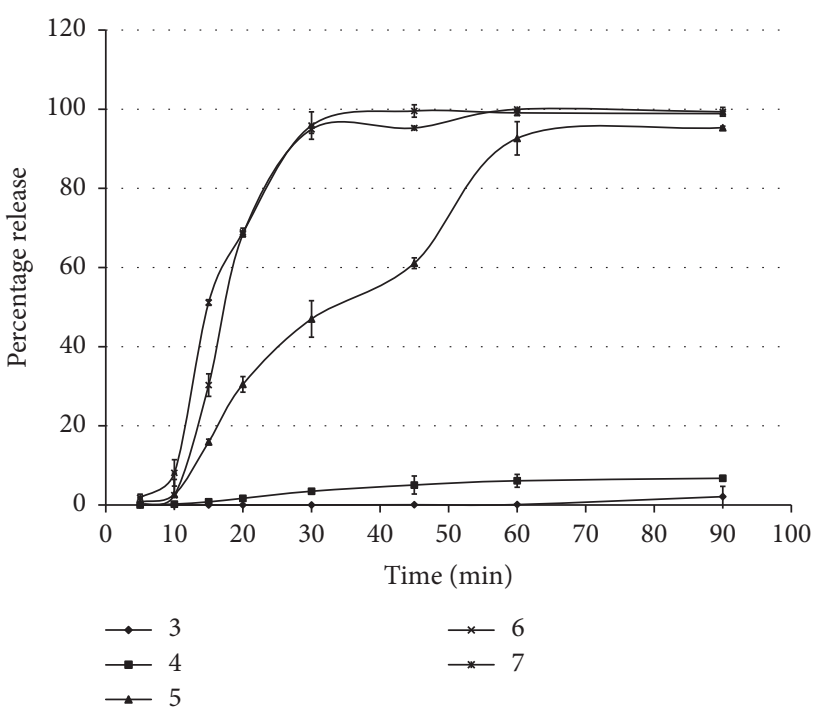

Figure 3: PB release from $1 \%$ Alg-PB beads at $\mathrm{pH}$ of 3, 4, 5, 6, and 7. Error bars represent standard deviation about the means based on 3 $\times 6$ replicates.

$\mathrm{CaCl}_{2}$, which shrinks at acidic $\mathrm{pH}$ and erodes at alkaline $\mathrm{pH}$. Sodium alginate has therefore been used effectively to deliver drugs to the intestine, which has a $\mathrm{pH}$ of $>6.7[24,25]$. Moreover, alginate is mucoadhesive and is likely to stick to intestinal mucosa for prolonged periods of time, thereby increasing the time for which the formulation will be available for local action [26, 27]. Further, alginates have also been reported to bind strontium, though no effort was made in the present study to validate this observation [28].

3.4. Analysis of Release Mechanism. Table 2 gives the mean correlation coefficient and release constants of various kinetic models. Hixson-Crowell mechanism of release was found the best fit model for explaining the release of PB from alginate beads. The graphic of the cubic root of the unreleased fraction of $\mathrm{PB}$ versus time was found to be linear and the correlation coefficients for all the systems (A to D) were approaching 1, suggesting that Alg-PB beads were following Hixson-Crowell mechanism of release, with the drug being released from Alg-PB beads as they were getting eroded with time. The data fitted to the Hixson-Crowell equation showed a correlation coefficient of 0.991 to 0.997 in all the four formulations and $K$ value showed a decreasing order with increase in polymer content. According to Hixson-Crowell model, geometrical shape of the dosage form diminishes with time until equilibrium is achieved and the release rate is limited by drug particles' dissolution rate and not by diffusion that might occur through the polymeric matrix [29]. Moreover, PB being an insoluble drug, therefore the drug could not get released by diffusion through the polymeric matrix.

3.5. In Vitro Binding Efficacy for ${ }^{201} \mathrm{Tl}$. PB has been used both in animals and in humans as antidote in case of thallium poisoning. US-FDA has accorded its approval to $\mathrm{PB}$ to be 
TABLE 2: Comparison of results of the fit to various release models.

\begin{tabular}{lccccc}
\hline Release models & & $\mathrm{A}$ & $\mathrm{B}$ & $\mathrm{C}$ & $\mathrm{D}$ \\
\hline \multirow{2}{*}{ Zero order } & $K$ & $0.042 \pm 0.007$ & $0.042 \pm 0.004$ & $0.047 \pm 0.004$ & $0.051 \pm 0.005$ \\
& $R^{2}$ & $0.863 \pm 0.103$ & $0.842 \pm 0.102$ & $0.947 \pm 0.019$ & $0.951 \pm 0.028$ \\
\hline \multirow{2}{*}{ First order } & $K$ & $0.22 \pm 0.095$ & $0.163 \pm 0.058$ & $0.126 \pm 0.047$ & $0.126 \pm 0.041$ \\
& $R^{2}$ & $0.971 \pm 0.040$ & $0.949 \pm 0.041$ & $0.995 \pm 0.001$ & $0.974 \pm 0.023$ \\
\hline \multirow{2}{*}{ Higuchi } & $K$ & $0.318 \pm 0.03$ & $0.294 \pm 0.028$ & $0.309 \pm 0.030$ & $0.345 \pm 0.033$ \\
& $R^{2}$ & $0.9502 \pm 0.02595$ & $0.902 \pm 0.083$ & $0.974 \pm 0.007$ & $0.993 \pm 0.001$ \\
\hline \multirow{2}{*}{ Hixson-Crowell } & $K$ & $0.299 \pm 0.121$ & $0.249 \pm 0.062$ & $0.218 \pm 0.056$ & $0.220 \pm 0.051$ \\
& $R^{2}$ & $0.998 \pm 0.007$ & $0.997 \pm 0.043$ & $0.993 \pm 0.006$ & $0.991 \pm 0.009$ \\
\hline \multirow{3}{*}{ Weibull Equation } & $b$ & $1.687 \pm 0.271$ & $1.755 \pm 0.216$ & $1.970 \pm 0.159$ & $13.417 \pm 0.159$ \\
& $\mathrm{Td}$ & $8.955 \pm 0.027$ & $9.529 \pm 0.216$ & $0.979 \pm 0.024$ & $14.356 \pm 0.300$ \\
& $R^{2}$ & $0.985 \pm 0.006$ & $0.985 \pm 0.024$ & $0.979 \pm 0.015$ \\
\hline \multirow{2}{*}{ Korsmeyer-Peppas } & $K$ & $0.16 \pm 0.057$ & $0.047 \pm 0.031$ & $0.009 \pm 0.047$ & $0.003 \pm 0.048$ \\
& $R^{2}$ & $0.994 \pm 0.007$ & $0.959 \pm 0.042$ & $0.968 \pm 0.021$ & $0.965 \pm 0.021$ \\
\hline
\end{tabular}

$K$, release rate constants; $R^{2}$, correlation coefficient; $n$, exponent release; Td, lag time measured as a result of the dissolution process; $b$, shape parameter of formulation.

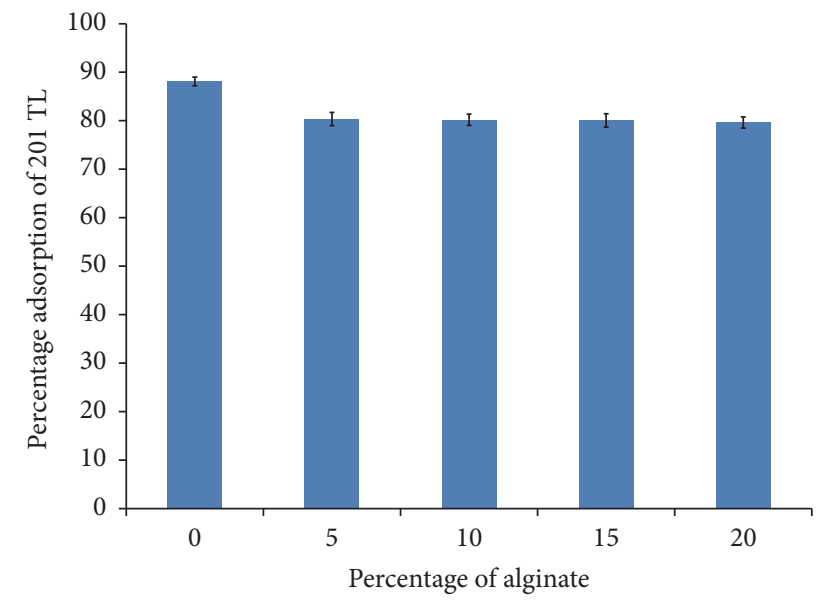

FIGURE 4: Adsorption efficiency of Alg-PB beads for ${ }^{201} \mathrm{Tl}$. Error bars represent standard deviation about the means based on three replicates.

used for the removal of ${ }^{137} \mathrm{Cs}$ and ${ }^{201} \mathrm{Tl}[6]$. Therefore, in order to study the efficacy of $\mathrm{PB}$ incorporated in alginate bead matrix, powdered Alg-PB formulations A, B, C, and D were incubated with ${ }^{201} \mathrm{Tl}$ for a period of $1 \mathrm{~h}$ as per previously reported method from our laboratory [2]. The results of this experiment showed $88.26 \pm 1.51 \%$ adsorption of ${ }^{201} \mathrm{Tl}$ by $1 \mathrm{mg}$ of native $\mathrm{PB}$ and $82.66,82.37,81.33$, and $80.73 \%$ adsorption by $1 \mathrm{mg}$ of powdered formulations $\mathrm{A}, \mathrm{B}, \mathrm{C}$, and $D$, respectively (Figure 4 ). The results thus obtained indicate that the binding efficacy of PB does not significantly reduce after its incorporation in the calcium alginate matrix.

3.6. Pharmacoscintigraphy Evaluation. Release profile of radioactivity $\left({ }^{99 \mathrm{~m}} \mathrm{TcO}_{4}{ }^{-}\right)$from technetium pertechnetate loaded Alg-PB beads showed a biphasic release curve when percentage cumulative counts released were plotted against

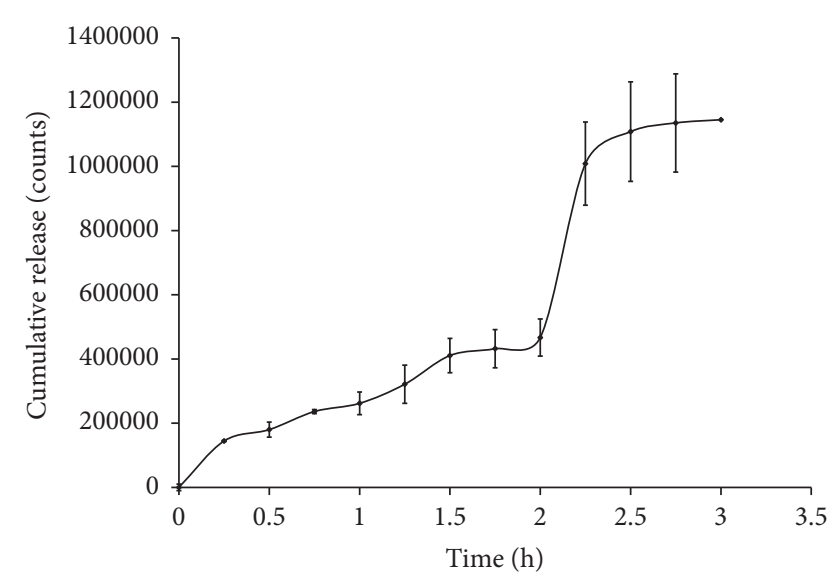

FIGURE 5: Release profile of radioactivity (technetium-99m pertechnetate, ${ }^{99 \mathrm{~m}} \mathrm{TcO}_{4}{ }^{-}$) from ${ }^{99 \mathrm{~m}} \mathrm{TcO}_{4}{ }^{-}$loaded Alg-PB beads.

time (Figure 5). The first phase was a slow release phase in acidic $\mathrm{pH}$ of $1-2$. Approximately $40 \%$ of total radioactivity was released in acidic media till $2 \mathrm{~h}$ and the rest was released within next $30 \mathrm{~min}$ in phosphate buffer of $\mathrm{pH}$ 6.8. However, no release of $\mathrm{PB}$ was observed in acidic media, but free pertechnetate being water soluble and a small moiety diffused out of the alginate bead matrix in acidic media of $\mathrm{pH}$ of 1-2 with a very slow rate. At higher $\mathrm{pH}$ of 6.8 , the rate of release was faster and $70 \%$ activity got released within $70 \mathrm{~min}$. Therefore, assuming that when radiolabeled beads are in stomach, slow release of radioactivity will occur and as free pertechnetate is released in stomach by the formulation, it will be immediately absorbed into the systemic circulation [30]. Similarly, as the beads will enter intestines, due to the higher $\mathrm{pH}$, beads will erode and free pertechnetate will be released at a faster rate. Thus, the blood pool activity will increase sharply. With this concept, $\mathrm{pH}$-dependent release of Alg-PB was studied qualitatively in humans by monitoring the blood pool activity 


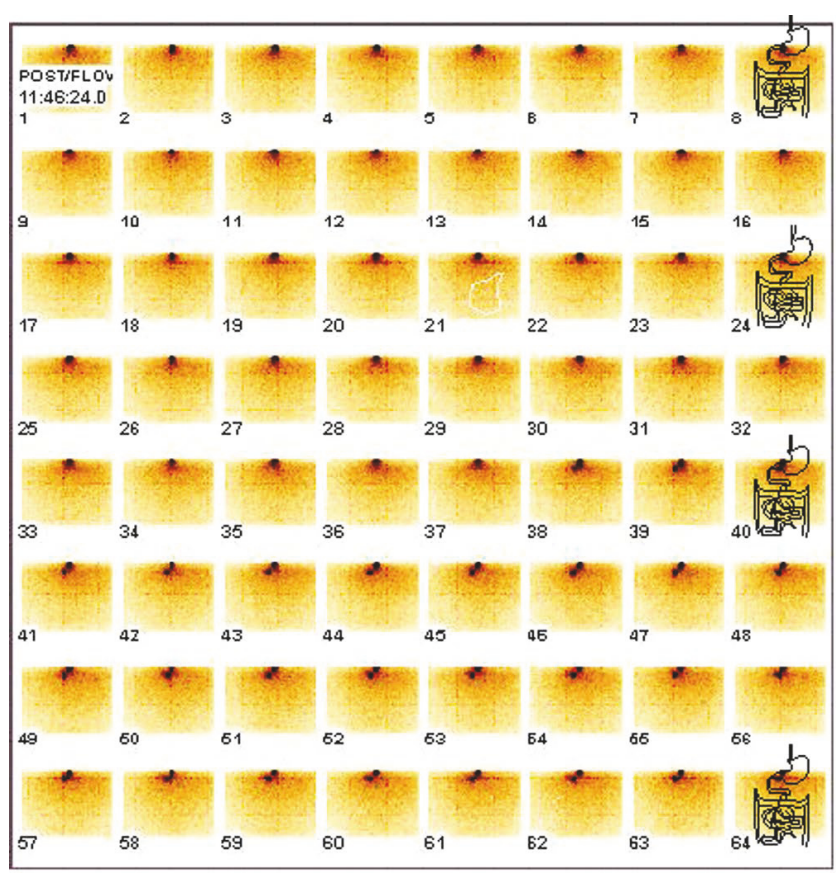

FIGURE 6: Image showing 32-minute continuous dynamic imaging of subject 1. Gamma camera was focused on lower abdomen and intestines. Each frame lasted for $30 \mathrm{sec}$ and the movements of beads were observed in 38th frame (at $19 \mathrm{~min}$ ).

with respect to position of beads in the GIT. Scintigraphic images were acquired immediately after administration of beads and 80 frames each of $30 \mathrm{sec}$ were taken. Scintigrams of radiolabeled Alg-PB beads in test subject showed the movement of beads in intestine after 20 min (Figure 6). Figure 6 is a 64 -frame dynamic gamma scintigraphy image of a human subject who has been given $200 \mathrm{mg}$ of ${ }^{99 \mathrm{~m}} \mathrm{Tc}$-labeled Alg-PB beads having $37 \mathrm{MBq}^{99 \mathrm{~m}} \mathrm{TcO}_{4}$. Each frame is of $30 \mathrm{sec}$ each. The dark spots in the frames are the ${ }^{99 \mathrm{~m}} \mathrm{Tc}$-labeled Alg-PB beads. These beads also contain some loosely bound, untrapped ${ }^{99 \mathrm{~m}} \mathrm{TcO}_{4}$ in free form, which gets released from these beads immediately and can be seen in the blood pool as tiny spots spread over in each frame. Blood pool activity was monitored by making region of interest (ROI) over liver and heart, and radioactivity of ROI was plotted as counts/sec versus time and shown subsequently in Figure 7, which shows a biphasic release. First phase existed till 20 min, until the time beads were in stomach. Second rapid release phase started after 20 min indicative of the release in intestine. First phase was found to be a slow release phase in which little amount of activity got absorbed in blood. On the other hand, after $20 \mathrm{~min}$, blood pool activity increased very sharply. The slope of the two phases was visually different. For control subjects

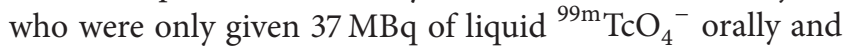
not given PB-Alg beads treatment, dynamic gamma scintigraphy images were not acquired because it is already reported that in such cases ${ }^{99}{ }^{\mathrm{TcO}_{4}}{ }^{-}$gets absorbed immediately and blood pool activity reaches very high levels within 2 min time [30]. These findings corroborated our in vitro release profile.

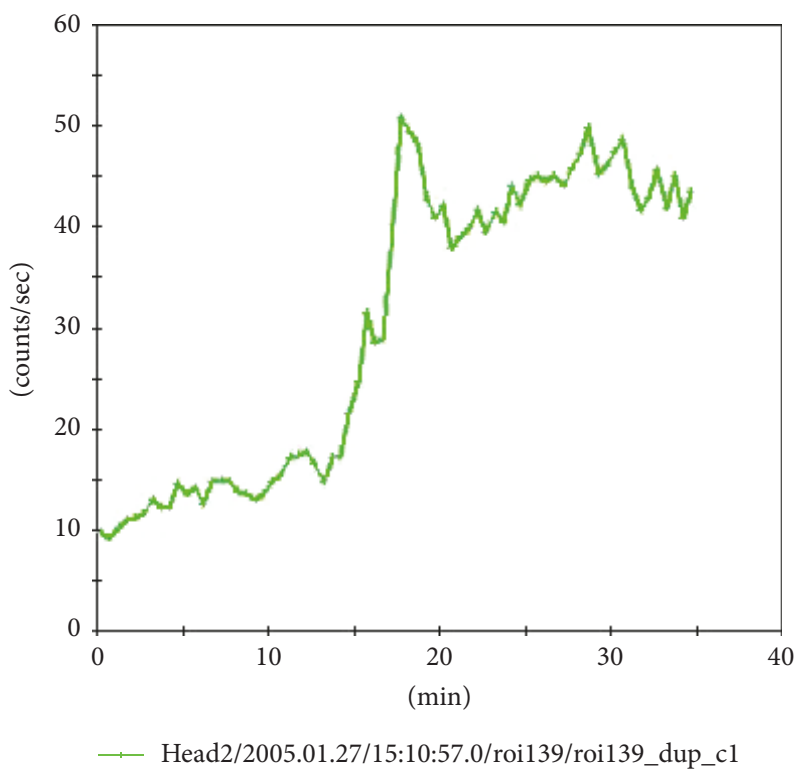

FIgURE 7: Graph showing the blood pool activity as counts per sec as a function of time.

In vitro and in vivo release profiles of radiolabeled Alg-PB beads were found to be superimposed. Both have a first slow release phase, suggesting that some amount of free pertechnetate leaches out of beads even at acidic $\mathrm{pH}$. As the beads come in contact with basic $\mathrm{pH}$ of 6.8 phosphate buffer in vitro and basic $\mathrm{pH}$ of intestines (duodenum), Alg-PB beads erode and entire amount of free pertechnetate is released rapidly.

Prussian blue $(\mathrm{PB})$ is an emergency/disaster management drug and not much of the related work has been done of it in the past. Post-Fukushima incident, there has been a renewed interest in developing strategies for radioactive cesium decontamination and decorporation using PB. However, much of the work reported for PB in last few years involves remediation of Cs-137 contaminated environments, primarily radiocontaminated water [31-35]. There is limited published literature on developing/improving countermeasures for internal decorporation of cesium from the body. The only formulation of Prussian blue approved by USFDA for internal decorporation is Radiogardase ${ }^{\circledR}$. Research groups from across the world are now trying to apply latest pharmaceutics principles to improve this conventional release capsule formulation, so as to improve its efficacy. Some efforts have been made in this direction, wherein preclinical studies in mouse model have been performed [36].

The present study has established the $\mathrm{pH}$-dependent delivery of PB from calcium alginate gel beads both in vitro and in vivo. Calcium alginate beads behaved as an erodible matrix, which at higher $\mathrm{pH}$ eroded to release $\mathrm{PB}$. Insignificant change in the adsorption efficacy of loaded and native $\mathrm{PB}$ was found during in vitro studies with ${ }^{201} \mathrm{Tl}$. In vivo pharmacoscintigraphic evaluation in healthy human volunteers proved the $\mathrm{pH}$-dependent release of the drug from PB-Alg beads. Thus, this study shows that the developed formulation can be used to achieve the intestinal release of $\mathrm{PB}$, with a possibility of increasing its efficacy at a lower dose. 


\section{Conflicts of Interest}

The authors declare that there are no personal or financial conflicts of interest with individuals or organizations.

\section{References}

[1] A. K. Vipin, B. Hu, and B. Fugetsu, "Prussian blue caged in alginate/calcium beads as adsorbents for removal of cesium ions from contaminated water," Journal of Hazardous Materials, vol. 258-259, pp. 93-101, 2013.

[2] N. Bhardwaj, A. Bhatnagar, D. P. Pathak, and A. K. Singh, "Dynamic, equilibrium and human studies of adsorption of 201Tl by prussian blue," Health Physics Journal, vol. 90, no. 3, pp. 250-257, 2006.

[3] D. F. Thompson and C. O. Church, "Prussian blue for treatment of radiocesium poisoning," Pharmacotherapy, vol. 21, no. 11, pp. 1364-1367, 2001.

[4] B. Dresow, P. Nielsen, R. Fischer, A. A. Pfau, and H. H. Heinrich, "In vivo binding of radiocesium by two forms of prussian blue and by ammonium iron hexacyanoferrate (ii)," Clinical Toxicology, vol. 31, no. 4, pp. 563-569, 1993.

[5] J. Kravzov, C. Rios, M. Altagracia, A. Monroy-Noyola, and F. López, "Relationship between physicochemical properties of prussian blue and its efficacy as antidote against thallium poisoning," Journal of Applied Toxicology, vol. 13, no. 3, pp. 213216, 1993.

[6] https://www.accessdata.fda.gov/drugsatfda_docs/label/2008/ 021626s007lbl.pdf.

[7] D. R. Melo, J. L. Lipsztein, R. Leggett, L. Bertelli, and R. Guilmette, "Efficacy of prussian blue on 137Cs decorporation therapy," Health Physics Journal, vol. 106, no. 5, pp. 592-597, 2014.

[8] P. W. I. Pau, "Management of thallium poisoning," Hong Kong Medical Journal, vol. 6, pp. 316-318, 2000.

[9] A. R. Oliveira, J. G. Hunt, N. J. Valverde, C. E. Brandao-Mello, and R. Farina, "Medical and related aspects of the goiania accident: an overview," Health Physics Journal, vol. 60, no. 1, pp. $17-24,1991$.

[10] D. R. Melo, J. L. Lipsztein, C. A. N. De Oliveira, and L. Bertelli, “ ${ }^{137} \mathrm{cs}$ internal contamination involving a brazilian accident, and the efficacy of prussian blue treatment," Health Physics Journal, vol. 66, no. 3, pp. 245-252, 1994.

[11] G. De Groot and A. N. P. Van Heijst, "Toxicokinetic aspects of thallium poisoning: methods of treatment by toxin elimination," Science of the Total Environment, The, vol. 71, no. 3, pp. 411-418, 1988.

[12] K. Y. Lee and D. J. Mooney, "Alginate: properties and biomedical applications," Progress in Polymer Science, vol. 37, no. 1, pp. 106126, 2012.

[13] R. Gong, C. Li, S. Zhu, Y. Zhang, Y. Du, and J. Jiang, "A novel $\mathrm{pH}$-sensitive hydrogel based on dual crosslinked alginate/ $\mathrm{N}-\alpha$ glutaric acid chitosan for oral delivery of protein," Carbohydrate Polymers, vol. 85, no. 4, pp. 869-874, 2011.

[14] B. B. Lee, P. Ravindra, and E. S. Chan, "Size and shape of calcium alginate beads produced by extrusion dripping," Chemical Engineering \& Technology, vol. 36, pp. 1627-1642, 2013.

[15] P. Nagaraja, N. D. Dinesh, N. M. Made Gowda, and K. S. Rangappa, "A simple spectrophotometric determination of some phenothiazine drugs in pharmaceutical samples," Analytical Sciences, vol. 16, no. 11, pp. 1127-1131, 2000.
[16] International Conference on Harmonization (ICH), Text on Validation of Analytical Procedures; Definition and Terminology, vol. 60, US FDA Federal Register, 1995.

[17] J. G. Wagner, "Interpretation of percent dissolved-time plots derived from in vitro testing of conventional tablets and capsules," Journal of Pharmaceutical Sciences, vol. 58, no. 10, pp. 1253-1257, 1969.

[18] M. Gibaldi and S. Feldman, "Establishment of sink conditions in dissolution rate determinations - theoretical considerations and application to nondisintegrating dosage forms," Journal of Pharmaceutical Sciences, vol. 56, no. 10, pp. 1238-1242, 1967.

[19] T. Higuchi, "Mechanism of sustained-action medication. Theoretical analysis of rate of release of solid drugs dispersed in solid matrices," Journal of Pharmaceutical Sciences, vol. 52, no. 12, pp. 1145-1149, 1963.

[20] A. W. Hixson and J. H. Crowell, "Dependence of reaction velocity upon surface and agitation: I-theoretical consideration," Industrial \& Engineering Chemistry, vol. 23, no. 8, pp. 923-931, 1931.

[21] F. Langenbucher, "Linearization of dissolution rate curves by the Weibull distribution," Journal of Pharmacy and Pharmacology, vol. 24, no. 12, pp. 979-981, 1972.

[22] N. A. Peppas, "Analysis of Fickian and non-Fickian drug release from polymers," Pharmaceutica Acta Helvetiae, vol. 60, no. 4, pp. 110-111, 1985.

[23] R. W. Korsmeyer, R. Gurny, E. Doelker, P. Buri, and N. A. Peppas, "Mechanisms of solute release from porous hydrophilic polymers," International Journal of Pharmaceutics, vol. 15, no. 1, pp. $25-35,1983$.

[24] A. A. Al-Kahtani and B. S. Sherigara, "Controlled release of diclofenac sodium through acrylamide grafted hydroxyethyl cellulose and sodium alginate," Carbohydrate Polymers, vol. 104, no. 1, pp. 151-157, 2014.

[25] S. K. Vemula, P. R. Veerareddy, and V. R. Devadasu, "Pharmacokinetics of colon-specific $\mathrm{pH}$ and time-dependent flurbiprofen tablets," European Journal of Drug Metabolism and Pharmacokinetics, vol. 40, no. 3, pp. 301-311, 2015.

[26] A. S. Patel, P. Saikat, and P. R. Pravinbhai, "Mucoadhesive microspheres containing anti-hypertensive agent: Formulation and characterization," Current Drug Delivery, vol. 11, no. 3, pp. 322-331, 2014

[27] T. Vincent, J.-M. Taulemesse, A. Dauvergne, T. Chanut, F. Testa, and E. Guibal, "Thallium(I) sorption using Prussian blue immobilized in alginate capsules," Carbohydrate Polymers, vol. 99, pp. 517-526, 2014.

[28] C. Gok, U. Gerstmann, and S. Aytas, "Biosorption of radiostrontium by alginate beads: application of isotherm models and thermodynamic studies," Journal of Radioanalytical and Nuclear Chemistry, vol. 295, no. 1, pp. 777-788, 2013.

[29] P. Costa and J. M. Sousa Lobo, "Modeling and comparison of dissolution profiles," European Journal of Pharmaceutical Sciences, vol. 13, no. 2, pp. 123-133, 2001.

[30] R. J. Kowalsky and R. J. Perry, Radiopharmceuticals in Nuclear Medicine Practice, Appleton \& Lange, California, Calif, USA, 1st edition, 1987.

[31] S.-C. Jang, S.-M. Kang, Y. Haldorai et al., "Synergistically strengthened 3D micro-scavenger cage adsorbent for selective removal of radioactive cesium," Scientific Reports, vol. 5, no. 6, Article ID 38384, 2016.

[32] A. K. Vipin, B. Fugetsu, I. Sakata et al., "Cellulose nanofiber backboned Prussian blue nanoparticles as powerful adsorbents 
for the selective elimination of radioactive cesium," Scientific Reports, vol. 15, no. 6, Article ID 37009, 2016.

[33] K. Minami, K. Sakurai, R. Kanai et al., "Radiocesium removal system for environmental water and drainage," Water Research, vol. 15, no. 107, pp. 29-36, 2016.

[34] Y. Kamachi, M. B. Zakaria, N. L. Torad et al., "Hydrogels containing Prussian blue nanoparticles toward removal of radioactive cesium ions," Journal of Nanoscience and Nanotechnology, vol. 16, no. 4, pp. 4200-4204, 2016.

[35] S. Jang, S. Hong, H. Yang et al., "Removal of radioactive cesium using prussian blue magnetic nanoparticles," Nanomaterials, vol. 4, no. 4, pp. 894-901, 2014.

[36] I. Tanaka, H. Ishihara, H. Yakumaru et al., "Comparison of absorbents and drugs for internal decorporation of radiocesium: advances of polyvinyl alcohol hydrogel microsphere preparations containing magnetite and Prussian blue," Biological \& Pharmaceutical Bulletin, vol. 39, no. 3, pp. 353-360, 2016. 

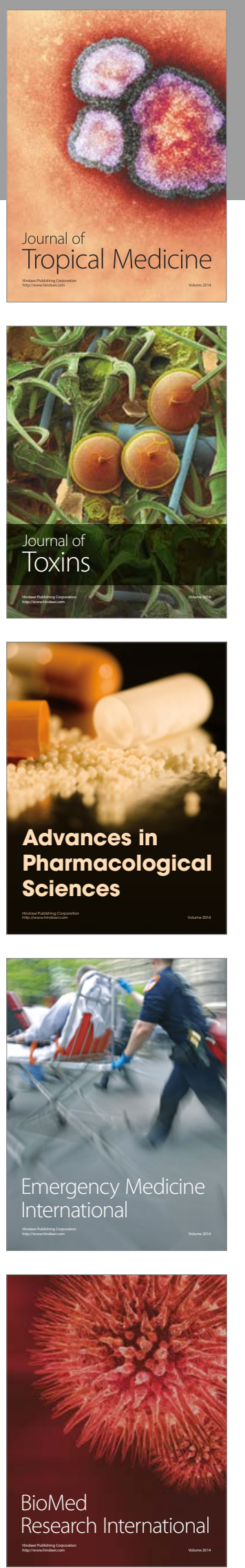
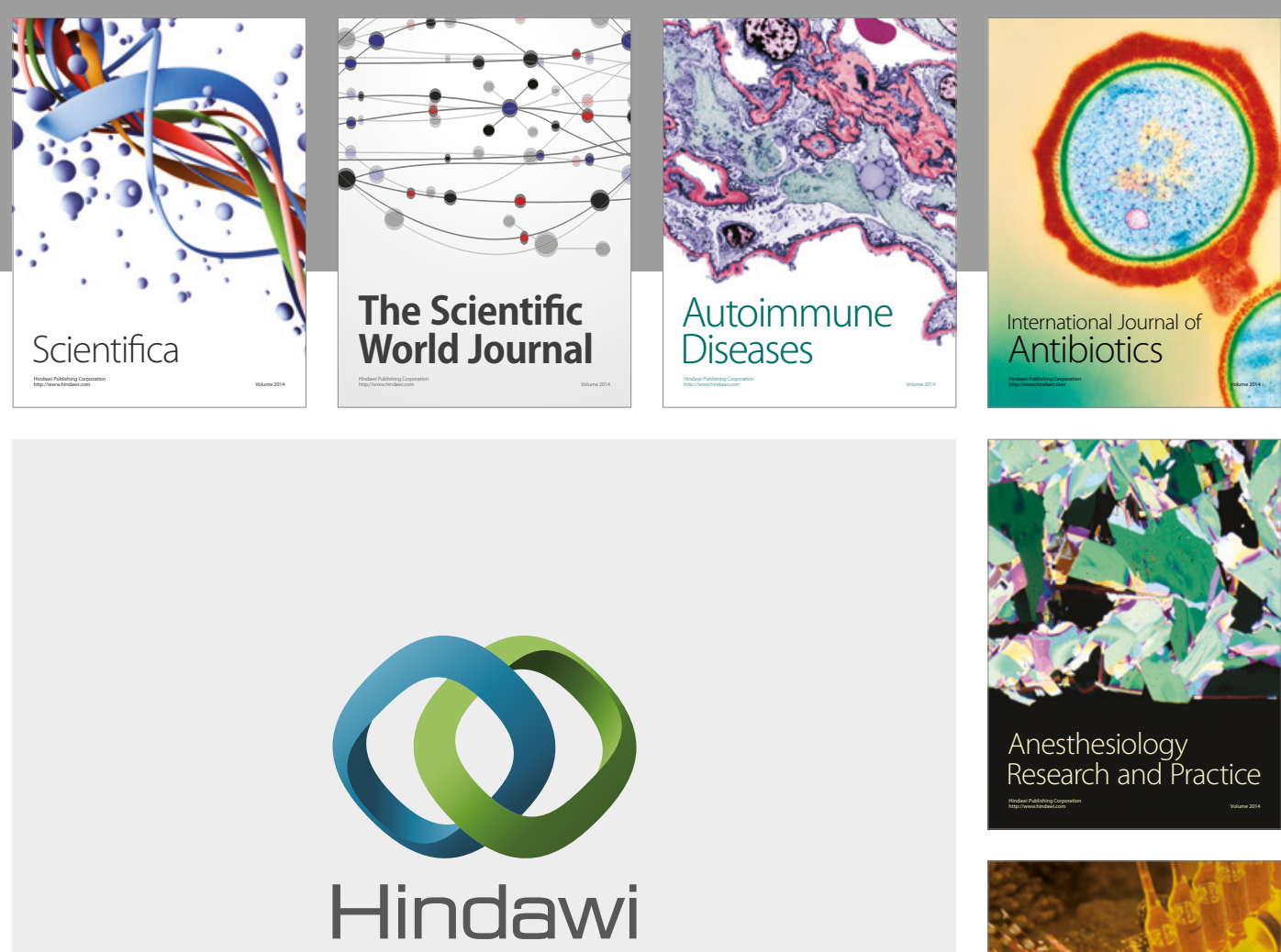

Submit your manuscripts at

https://www.hindawi.com
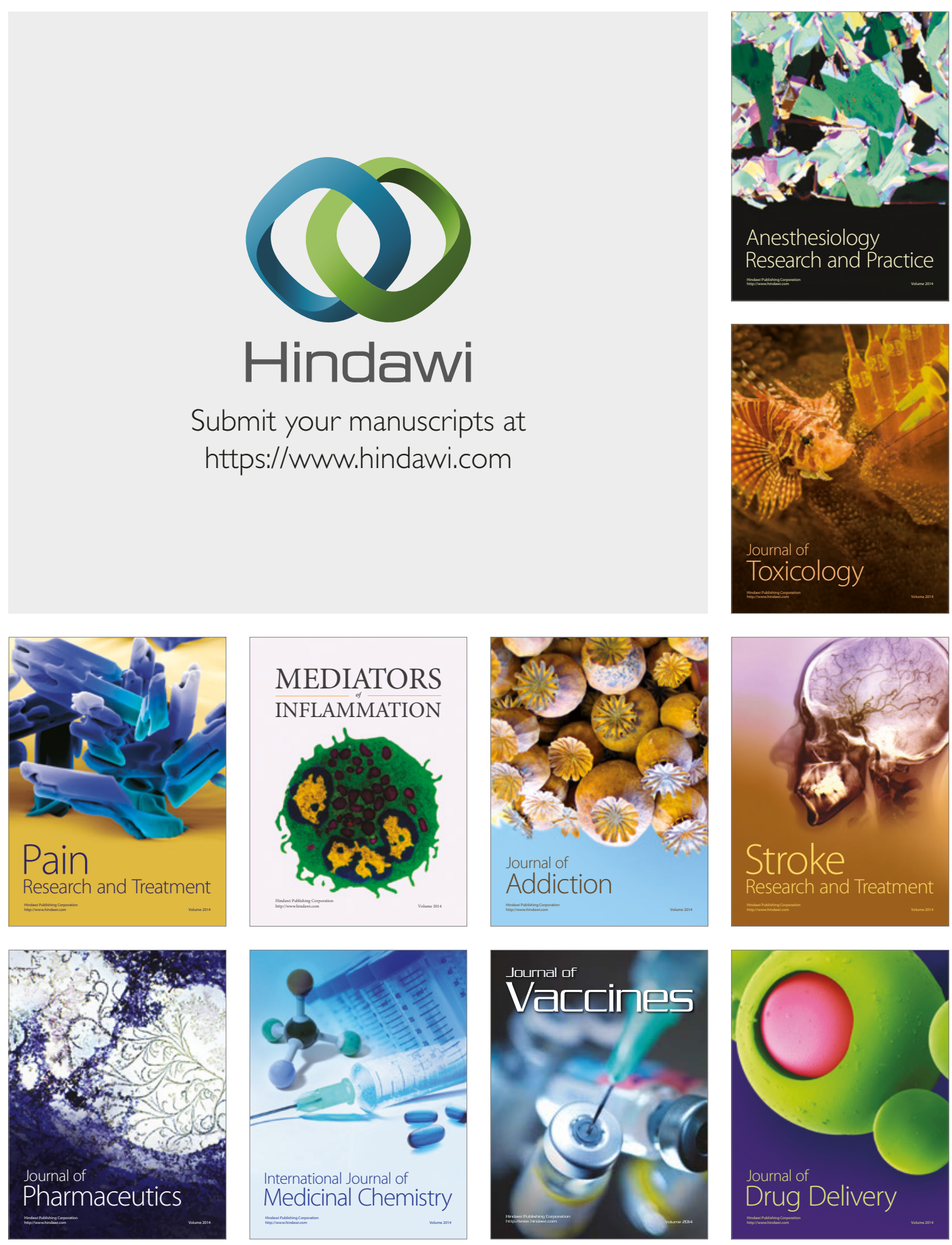